\title{
OPTIKS: Outreach for professionals who teach in informal environments and $\mathrm{K}-12$ schools
}

\section{Mike McKee, Nancy Magnani, Matthew Posner}

Mike McKee, Nancy Magnani, Matthew T. Posner, "OPTIKS: Outreach for professionals who teach in informal environments and K-12 schools," Proc. SPIE 11143, Fifteenth Conference on Education and Training in Optics and Photonics: ETOP 2019, 111432M (2 July 2019); doi: 10.1117/12.2520818 Photonics: ETOP 2019, 2019, Quebec City, Quebec, Canada 


\title{
OPTIKS: Outreach for Professionals who Teach in Informal Environments and K-12 Schools
}

\author{
Mike McKee*,a Nancy Magnani ${ }^{\mathrm{b}}$, Matthew T. Posner ${ }^{\mathrm{c}}$ \\ ${ }^{a}$ CREOL, The College of Optics and Photonics, University of Central Florida, 4304 Scorpius Street, \\ Orlando, Florida 32816, USA \\ ${ }^{\mathrm{b}}$ Sumner School District \#320, 1202 Wood Ave, Sumner, WA, 98390, USA \\ ${ }^{\mathrm{c} E x c e l i t a s}$ Technologies Inc., 22001 Chemin Dumberry, Vaudreuil-Dorion, QC J7V 8P7, Canada
}

\begin{abstract}
OPTIKS, Outreach for Professionals who Teach in Informal Environments and K-12 Schools, is an interactive workshop for industry professionals, graduate students or faculty who are interested in presenting outreach and training others in how to conduct workshops. The paper outlines the components of this class for participants to understand how to develop lessons and activities to engage prospective audiences about optics and photonics science and technology. Key preparation considerations, such as audience and location, are presented alongside formal pedagogical methods to develop highly engaging outreach education activities. The workshop was first implemented at the 2018 SPIE Optics + Photonics congress, and an overview of the delivery is be presented as a case study of this paper. Lessons learned from the initial presentation along with future improvements to this course will also be discussed in this paper.
\end{abstract}

Keywords: Photonics outreach, Public engagement, Continuous education.

\section{INTRODUCTION}

It is common for industry professionals, faculty, and graduate students to conduct outreach education to K-12 schools and in informal locations such as fairs, science centers, or open houses. But what are the most effective ways to engage participants in activities and how should the information be presented? OPTIKS, Outreach for Professionals who Teach in Informal Environments and K-12 Schools, is an interactive workshop for industry professionals, graduate students or faculty who are interested in presenting outreach and training others in how to conduct workshops. The workshop teaches participants how to most effectively present activities in optics and photonics that will maximize engagement while considering the audience and the location.

The outline of the paper will be as follows. Section 2 will provide details of the course, with focus on the pedagogy, key preparation considerations and ways for professionals to teach their own workshops in informal environments and K-12 schools. Section 3 will describe an implementation of the course and discuss results from the first delivery at the 2018 SPIE Optics + Photonics conference. Section 4 will conclude the paper with a summary of work to date and future perspectives.

*mmckee@creol.ucf.edu; phone +1 407-823-6376; www.creol.ucf.edu 


\section{COURSE OUTLINE}

Teaching in formal environments, such as classrooms, involves a great deal of planning in developing lessons, designing activities, and delivering content so that students will learn. Likewise, in informal learning environments such as science centers, technology fairs, or exhibitions, the level of planning needs to account for factors such as the audience, the environment and the interaction time with participants. An inquiry-based pedagogy model is used as a foundation for the course, and this will be introduced in this section. The importance of interactive techniques and effective communication will be outlined, and the section will conclude with suggestions for practical considerations presented in this course.

\subsection{ABC-CBV-RAL: a pedagogy for highly engaging lessons}

In the 1980s, the Biological Sciences Curriculum Study, now known as BSCS Science Learning, initiated a researchbased lesson plan model designed to engage students in learning, uncover misconceptions, and improve student outcomes. Called the $5 \mathrm{E}$ model ${ }^{1}$, it serves as the foundation for inquiry-based learning and helps for students to establish relationships between what they already know, what they will learn, and the ways that teachers can assess their learning. The model relies on the ability of conducting the lesson and associated assessment over a sustained period of time, which is compatible with classroom-based teaching. Active engagement methods, with activities and laboratory experiences at the core of the learning, have been applied in Physics Education ${ }^{2}$. The model is challenged for outreach activities, both in formal and informal environments.

The active engagement model is extended here to help prepare activities that are inquiry-based and compatible with outreach education activities. First, activities are designed to engage students in meaningful ways, whereby they capture the attention and create the conditions where students must apply key critical thinking and problem-solving skills. Such activities enable a better understanding of scientific concepts. The discussion and sharing of these concepts naturally lead to better understanding of the associated vocabulary, which teachers can thoroughly discuss at the end of the activity. Reading is critical to understanding the subject. The model proposed encourages students to read at the end. The process flow is defined as Activity before Concept (ABC), Concept before Vocabulary (CBC) and Reading at last (RAL), which is illustrated in Figure 1. Traditional teaching may require reading before the classroom and, in this approach, the engagement activity becomes the pre-reading activity.

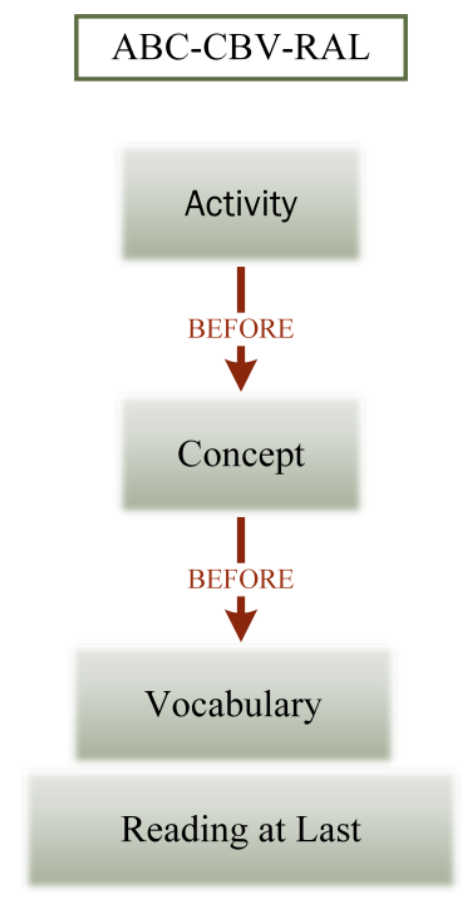

Figure 1. ABC-CBV-RAL: a model for designing inquiry-based activities. 


\subsection{Interactive techniques and effective communication}

Interactive techniques can be used in formal and informal settings. The intrinsic benefits to the participants are revived from their passivity of merely listening to a lecture, instead becoming attentive and engaged, two prerequisites for effective learning. These techniques are often perceived as "fun", yet they are frequently more effective than lectures at enabling student learning. There are many techniques, including, but not limited to, opinion polls, think-pair-share, brainstorms or four corners; a full list would be too comprehensive for the scope of this report and the reader is referred to the works of Angelo et al. ${ }^{3}$ and Morrison-Shetlar et al. ${ }^{4}$ for details. A comprehensive list of techniques used in the context of this course is also available as a resource from the authors on request.

The ABC-CBV-RAL approach is intended to permit students to become more fluid in using scientific vocabulary. For example, an audience may not be aware of the term "refraction" with respect to light transmitted through a lens. Prior to an experiment, participants can be challenged to think about what happens when light goes through a lens. Participants may say light bends or focuses. Later, after participants experiment with such phenomena, complex terminology that is specifically tied to the activity can be introduced. The pedagogy encourages the use of terms that are more common across many disciplines first, and then use experiences in the activity for the students to learn new content. A recommended preparation exercise to the expert is to list terms often used in their research field and create a list of terminology that can be used for audiences of different backgrounds, thus being able to speak simply or appropriately with the audience.

The design of the activity itself may take into consideration other factors, such as the gender of the audience. A recent report outlined that activities that are collaborative, not elitist, and include relatable role models and/or mothers may have greater impact on female audiences ${ }^{5}$. The choice of the descriptive language to describe careers can also be an important factor in the preparation of material; the use of adjective-oriented language instead of action-oriented language has been discussed in previous reports as a means for more effective engagement with a female audience ${ }^{6}$.

\subsection{Practical considerations}

The delivery of the activity will need to consider the setting, i.e. whether it is formal or informal. Formal settings are characterized by longer activities (labs, classes) with worksheet that develop one or two ideas, generally with activities tied to a curriculum and more time (30-60 minutes) for questions and the exploration of multiple concepts. Informal settings are generally characterized by shorter activities, with the need of grabbing attention quickly and little time to develop concepts, thus requiring ideas simple to communicate. These generalizations can help prepare an activity for a given audience and location.

A set of practical considerations for audience and location are outlined in Table 1. The reader is referred to the wider literature for further illustrative examples, and in particular previous proceedings of the Conference on Education and Training in Optics and Photonics (ETOP) and the Proceedings of the SPIE Optics Education and Outreach Conference.

Table 1. Checklist of considerations for location and audience when preparing an activity.

\begin{tabular}{|c|c|c|c|}
\hline \multicolumn{2}{|r|}{ Location } & \multicolumn{2}{|r|}{ Audience } \\
\hline$\square$ & Is the setting formal or informal? & & \\
\hline$\square$ & What is the format of the event? & $\square$ & What will be the interaction with th \\
\hline$\square$ & How much space will you have? & & participants? \\
\hline$\square$ & Is there electricity? & $\square$ & How many will be in attendance? \\
\hline$\square$ & What is the budget like? & $\square$ & Who is the audience? \\
\hline$\square$ & Are there enough supplies? & $\square$ & $\begin{array}{l}\text { How much time will there be for individual } \\
\text { activities and overall? }\end{array}$ \\
\hline$\square$ & $\begin{array}{l}\text { How will the activity be transported? } \\
\text { What other items are needed on display, }\end{array}$ & $\square$ & $\begin{array}{l}\text { How can the activity be explained using } \\
\text { simple language? }\end{array}$ \\
\hline$\square$ & $\begin{array}{l}\text { Will the items be organized for rapid } \\
\text { deployment? }\end{array}$ & $\square$ & Is the activity relevant to the audience? \\
\hline
\end{tabular}




\subsection{Teaching others}

Part of this workshop is to learn how to engage participants in their own learning and create the feeling within an individual of "why do I want to know this?" The same should apply for the reader wishing to conduct this workshop with others, i.e. to model all the engagement techniques conducted. Often, teachers or presenters are reluctant to use an inquiry-based model because they say they don't know all the possible answers which may come up from the various questions. The best answer to an unknown question is "I don't know but let's try some things to find out" and use this as an opportunity for further learning. This behavior will encourage exploration of new concepts. The same philosophy is used in the delivery of the workshop, which is presented in the following section.

\section{COURSE DELIVERY}

The following section describes the course's first implementation at the 2018 SPIE Optics + Photonics (O+P) Symposia, San Diego, CA. Course evaluation results are presented for the reader to understand the outcomes from presenting a course at the $\mathrm{O}+\mathrm{P}$ symposia.

\subsection{The course in practice: making use of interactive techniques}

The workshop was designed as a 4-hour course and was attended by 12 participants. The participants were split into three work groups, organized around pairs of tables - see Figure 2 (a). The class focused on introducing methods of teaching pedagogy following the ABC-CBV-RAL method. For instance, to introduce the interactive techniques "Think Pair Share" and "Four Corners", participants were asked to think of an outreach activity and what had made it successful. The participants then classified the importance of the factors of success following a " 4 corners" approach, where they were asked to move to corners of the room based on the criteria they selected and asked to justify it - see Figure 2 (b). The experience was used to then discuss the concepts linked to teaching methods, followed by introducing the vocabulary of the interactive techniques. Participants were invited to read about these techniques in the course book after the class, to complete the learning cycle.

A similar pedagogical approach was employed throughout the course to demonstrate the diversity of scenarios where the ABC-CBV-RAL method could be employed. These consisted of

- Redesigning a lesson for a female-only audience, based on the Seven Steps Method used by SciGirls Connect.

- Experiencing an activity on spectroscopy as it would be presented using ABC-CBV-RAL.

- Using T-charts to compare and contrast cookbook and inquiry-based activities, based on the imaging of a lightbulb through a lens.

- Adapting lessons in formal environments to be used in informal learning environments.

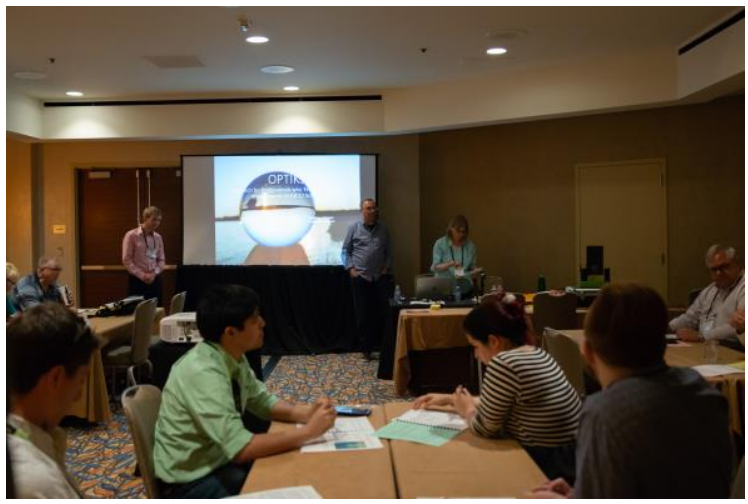

(a)

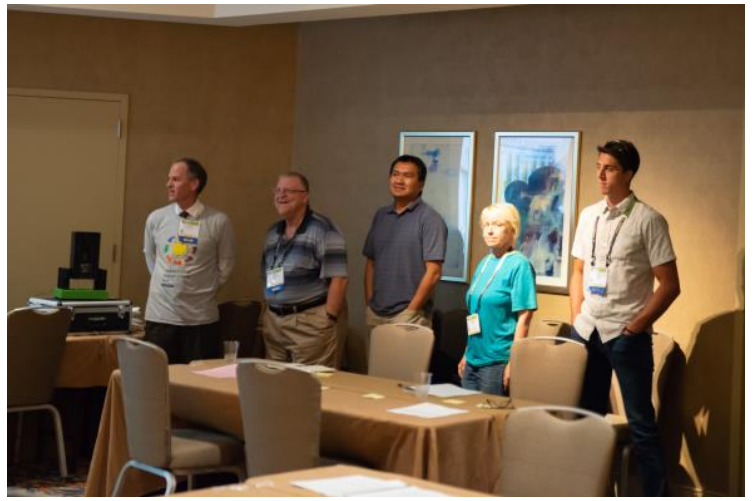

(b)

Figure 2. First workshop delivery at SPIE Optics + Photonics 2018. (a) Illustrative classroom layout for the course. Participants were divided into work groups for the some of the activities in the workshop. (b) Course attendees participating in a "Four Corners" discussion during the workshop. Photo credits Mr. Adam Resnick, SPIE. 
The modularity of the course permits for activities to be added or removed as function of audience and constraints, following considerations outlined in Table 1.

\subsection{Course feedback}

Participants were asked to evaluate the course based on 8 criteria using a 5-point Likert scale. Results were processed by the SPIE Education Services department. The feedback results were presented and compared with the symposium course average. Eight participant responses were considered in the evaluation summary. The course's average grade was of $4.61 / 5$, ranking close to the symposia average of 4.66/5. Table 2 classifies the feedback obtained with respect to the average grades of symposia courses. A challenge with trying to use the ABC-CBV-RAL approach with students is that it is very different from traditional learning experiences, with unusual succession of the course material. This may account for the lower marks on the organization and ease of following of course materials, which will be reviewed for future implementations. Additional verbatim feedback was obtained ("The course was fun and engaging"; "Great course and instructors"), providing positive input for continuation.

Table 2. Course feedback ranked with respect to symposia average for criteria used to evaluate the quality of the course.

\begin{tabular}{|c|c|c|}
\hline Potential improvements & Suitable & Strength \\
\hline $\begin{array}{l}\text { The instructor was well organized } \\
\text { and gave a clear presentation. } \\
\text { The course materials were clear and } \\
\text { easy to follow. }\end{array}$ & $\begin{array}{l}\text { The length of the course was } \\
\text { sufficient to cover the content } \\
\text { promised in the description. } \\
\text { Based on the quality of this course, I } \\
\text { would take another SPIE course. }\end{array}$ & $\begin{array}{l}\text { The instructor was knowledgeable } \\
\text { about the subject. } \\
\text { The course content matched the } \\
\text { stated learning outcomes. } \\
\text { The level of the course was as stated } \\
\text { in the course description. } \\
\text { The content of this course is } \\
\text { relevant to my work/professional } \\
\text { development. }\end{array}$ \\
\hline
\end{tabular}

\section{CONCLUSIONS AND FUTURE WORK}

This paper has introduced the ABC-CBV-RAL method for developing engaging lessons and reviewed the techniques for engagement, communication and preparation for carrying out outreach education activities in formal and informal environments. The first delivery of the course was described, with positive feedback from participants that will enable the course to progress. The course will be delivered again at the 2019 International Conference on Education and Training in Optics and Photonics and the 2019 SPIE Optics + Photonics Symposia. The course is intended to "train the trainers" and further grassroots initiatives will be explored to allow more widespread adoption of this model for professionals wishing to develop their own outreach education activities in formal and informal teaching environments.

\section{ACKNOWLEDGEMENTS}

The authors acknowledge: Kevin Yee and Lori Mumpower for ideas on additional interactive techniques that were presented in §2.2; and SPIE for permitting publication of course evaluation details and pictures taken at SPIE Optics + Photonics 2018.

\section{REFERENCES}

[1] Bybee, R. W., Taylor, J. A., Gardner, A., Van Scotter, P., Powell, J. C., Westbrook, A. and Landes, N., "The BSCS 5E Instructional Model: Origins and Effectiveness, Executive Summary," Colorado Springs, CO (2006). 
[3] Angelo, T. A. and Cross, T. P., [Classroom Assessment Techniques: A Handbook for College Teachers, 2nd ed.], Jossey-Bass, San Francisco (1993).

[4] Morrison-Shetlar, A. and Marwitz, M., [Teaching Creatively: Ideas in Action], Outernet Pub (2001).

[5] MacDonald, A., “'Not for people like me?' Under-represented groups in science, technology and engineering," 2014, <https://www.wisecampaign.org.uk/uploads/wise/files/not_for_people_like_me.pdf>.

[6] Wong, N. H. L., Posner, M. T. and John, P. V., "The Lightwave Programme and Roadshow : An Overview and Update," Proc. SPIE 9793 97932V, 1-16 (2015 